\title{
LAS EFIGIES DE FERNANDO VI EN MEXICO
}

\author{
P O R
}

\section{MANUEL ROMERO DE TERREROS}

$M$ IENTRAS a Carlos III algunos historiadores mexicanos elogian y otros censuran; mientras a Carlos IV la mayoria desprecia y a Fernando VII todos vituperan; en cambio, para los más, Fernando VI pasa casi inadvertido, siendo asi que su reinado fué el más pacífico e inciudablemente el más acertado gobierno que tuvo la Madre Patria en todo el siglo XvinI.

No es, pues, cosa extraña que en nuestro país existan pocas efigies del sexto de los Fernandos, y si de varios de sus sucesores. Por eso, tal vez no sea ocioso mencionar los retratos que del pacífico monarca se conocen en México.

Desde luego, en el Museo Nacional de Historia, en Chapultepec, se exhibe un cuadro al óleo, que representa a don Fernando, de tamaño natural, de pie, con peluca y lujosamente ataviado, viéndose al fondo, por un arco, algunos árboles y parte de una fuente de los jardines del Real Sitio de San Ildefonso, "La Granja". Está copiado este retrato de la figura de nuestro personaje, que forma parte del magnifico cuadro "La Familia de Felipe V", de Luis Miguel van Loo, que se admira en el Museo del Prado, en Madrid. Fué pintada esta copia en España, en época relativamente reciente.

No sabemos que haya en México otro retrato, al óleo, de don Fernando VI.

En escultura, existe un alto relieve de este rey en lo que queda del antiguo puente del Molino Prieto, en el camino de Tacuba a San Bartolo 
Naucalpan. Este puente, de piedra, tiene esculpidos en cada una de sus cabeceras o pretiles, por ambos lados, sendos óvalos en alto relieve $y$, debajo, cuadros con inscripciones alusivas, una de las cuales informa que el puente fué mandado construir en 1750, por "D. Fernando Gerónimo López de Peralta Villa-amil", y que fué obra de Juan José de Ocampo. Este artífice debe de haber sido hijo de Salvador de Ocampo, quien, en 1701, contrató la famosa sillería de coro de la Iglesia de San Agustín.

Los relieves interiores de los pretiles de este puente corresponden a las imágenes de Nuestra Señora de Loreto y San José, cada una con una invocación apropiada; mientras que los exteriores representan a don Fernando VI y a doña Bárbara de Braganza, ambos de media figura, el del rey empuñando el cetro en la diestra, y con la particularidad de que ostenta el collar de la orden del Toisón de Oro, en forma de banda, seguramente porque Ocampo no era muy ducho en cuestiones de heráldica. Las esculturas no carecen de mérito, aunque, como era de esperarse, se encuentran un tanto deterioradas.

Retrato de Fernando VI en litografia, es uno, no muy feliz, que ilustra el tercer tomo de las Disertaciones Históricas de Lucas Alamán, "sacado, dice el autor, del que se halla en los Titrulos de Castilla", de Berní; el cual está tomado, a su vez, del magnifico busto, al óleo, que pintó también Van Loo, y que preside el Salón de Actos de la Real Academia de Nobles de San Fernando, fundada por el rey, cuadro que Narciso Sentenach califica "de depurado alarde de dibujo y empaste", lo que demuestra que la copia de Berní fué defectuosísima.

Otro retrato del monarca, de mejor factura, dibujado por el artista mexicano Luis Garcés, y litografiado por Munguia, figura en Los Gobernantes de México, de Manuel Rivera Cambas. Representa al rey, de busto, de frente y con sombrero de tres picos.

Hay que hacer caso omiso de los retratos de Fernando VI, que ilustran algunas obras de historia, porque, como en México a través de los siglos, carecen de valor artístico o iconográfico.

Pero en donde se encuentra mayor número de efigies de este rey de España es en el campo de la numismática mexicana: desde luego, en las monedas de ocho, cuatro, dos y un escudos, emitidas desde 1747 hasta 1759. Presentan tres tipos diferentes, todos de busto mirando a la derecha, con voluminosa peluca a lo Luis XIV, armadura, banda, chorrera, y collar de la Orden del Toisón de Oro. 
Todavia de menor valor artístico son las efigies de don Fernando en las "Medallas de Proclamación", todas defectuosamente fundidas, que emitieron las ciudades de Córdoba, Cholula, Chihuahua, Guadalajara, Guanajuato, México, Puebla, San Miguel, Sombrerete y Veracruz, todas de busto con peluca, $y$ algunas con sombrero. Son excesivamente raras e interesantes desde el punto de vista numismático, pero nada más; no hay dos que parezcan representar al mismo personaje. En la de Sombrerete, por ejemplo, la cabeza de Fernando VI es la de un niño, coronado de laurel, que no tiene ni el más remoto parecido con las demás.

En conclusión, puede afirmarse que los retratos mexicanos de Fer1lando VI, fueron todos productos de la fantasía de cada artista, puesto que ninguno se parece al que sí es auténtico retrato del pacifico monarca, tomado, como hemos dicho, del famoso grupo de Van Loo "La Familia de Felipe V".

\section{BIBLIOGRAFIA}

F. J. Sánchez Cantón. Los Retratos de los Reyes de España. Barcelona, 1948.

Narciso Sentenach. Los Grandes Retratistas de España. Madrid, 1914.

Manuel Rivera Cambas. Los Gobernantes de Mérico. México, 1873.

Lucas Alamán. Disertaciones Históricas. Vol. III. México, 1849. 
DOI: http://dx.doi.org/10.22201/iie.18703062e.1954.22.571 
DOI: http://dx.doi.org/10.22201/iie.18703062e.1954.22.571

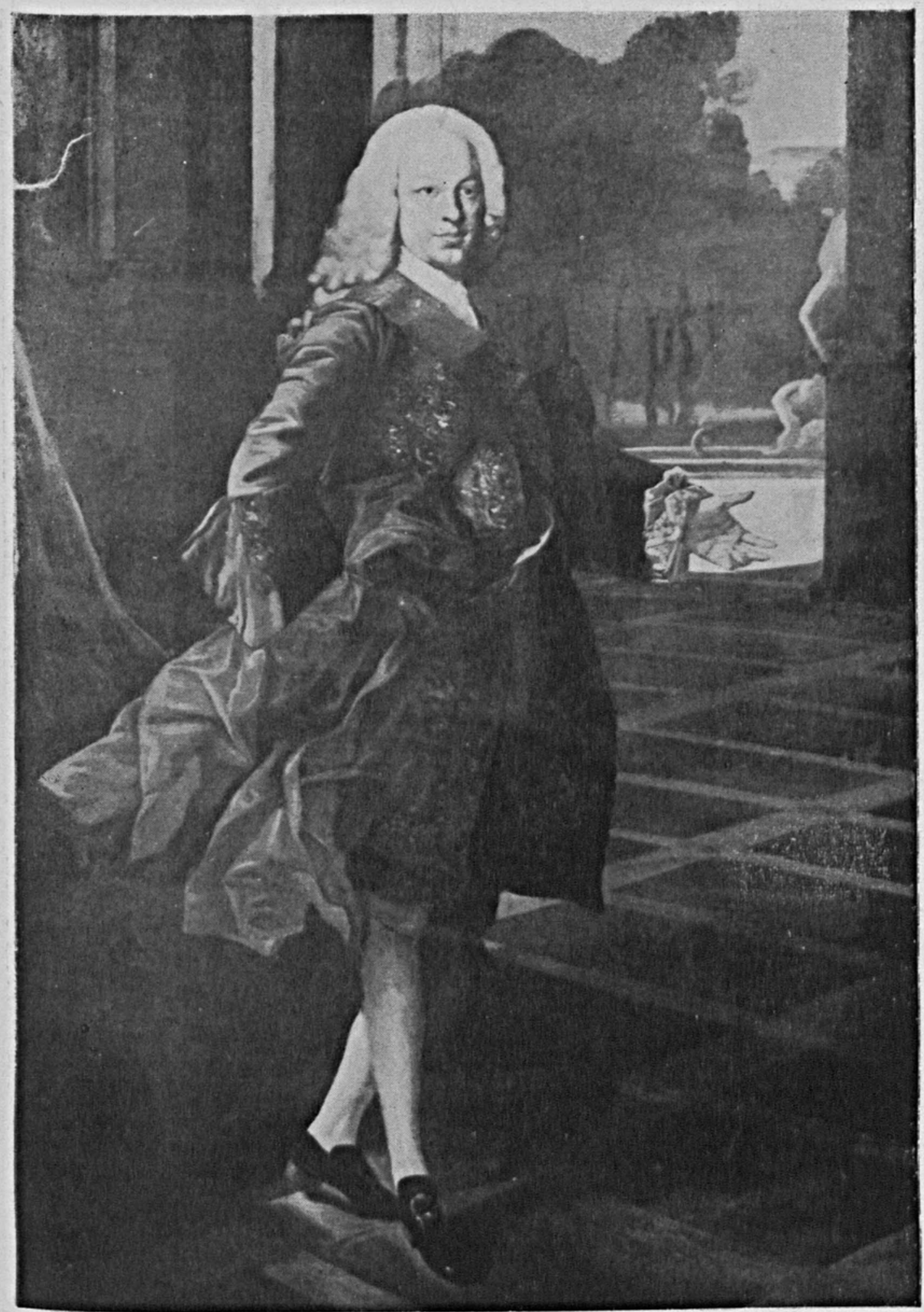

1. Fernando VI, del cuadro de Van Loo La Familia de Felipe $V$. (Museo del Prado. Madrid.) 


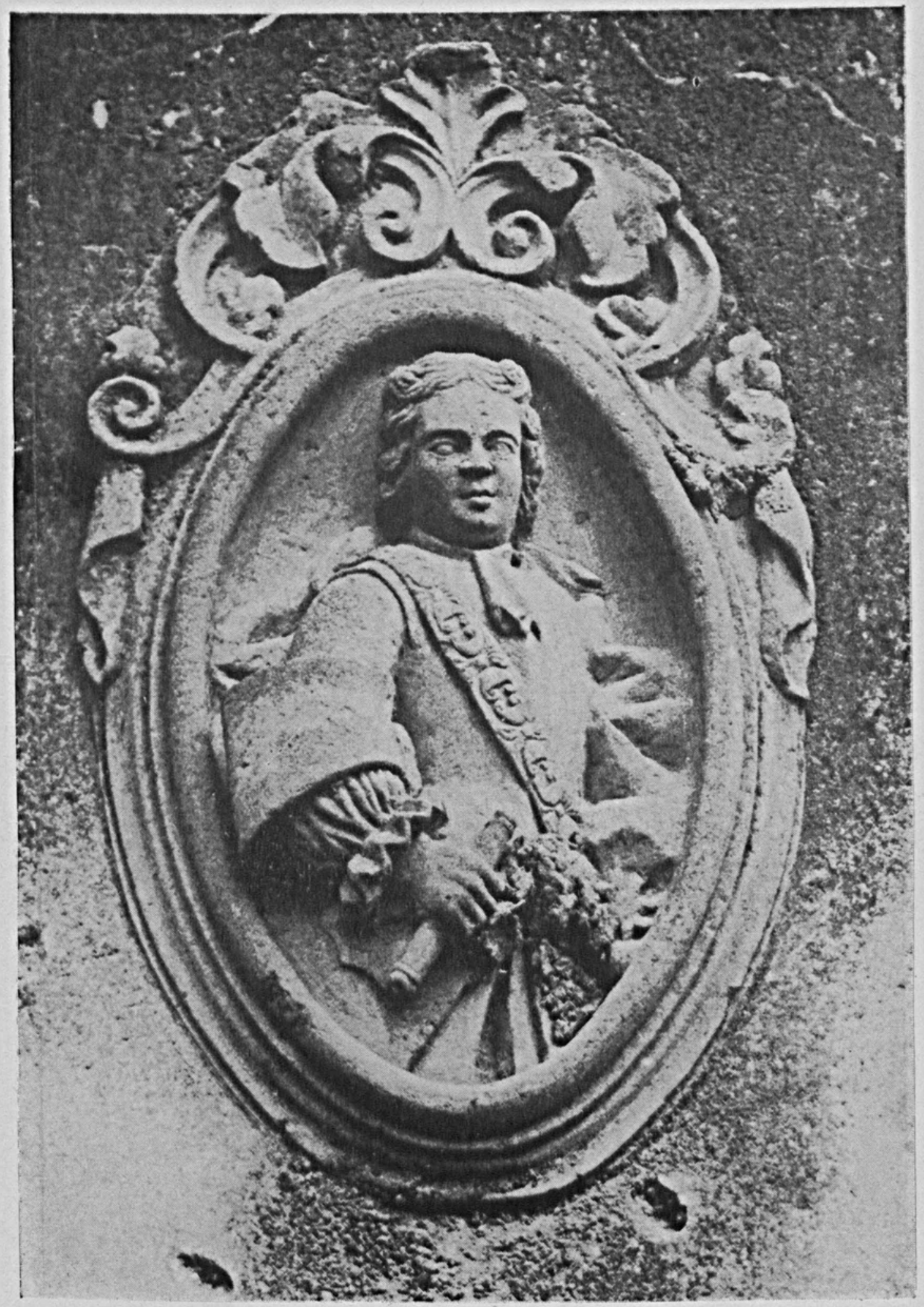

2. México, D. F. Relieve en el Puente del Molino Prieto. 


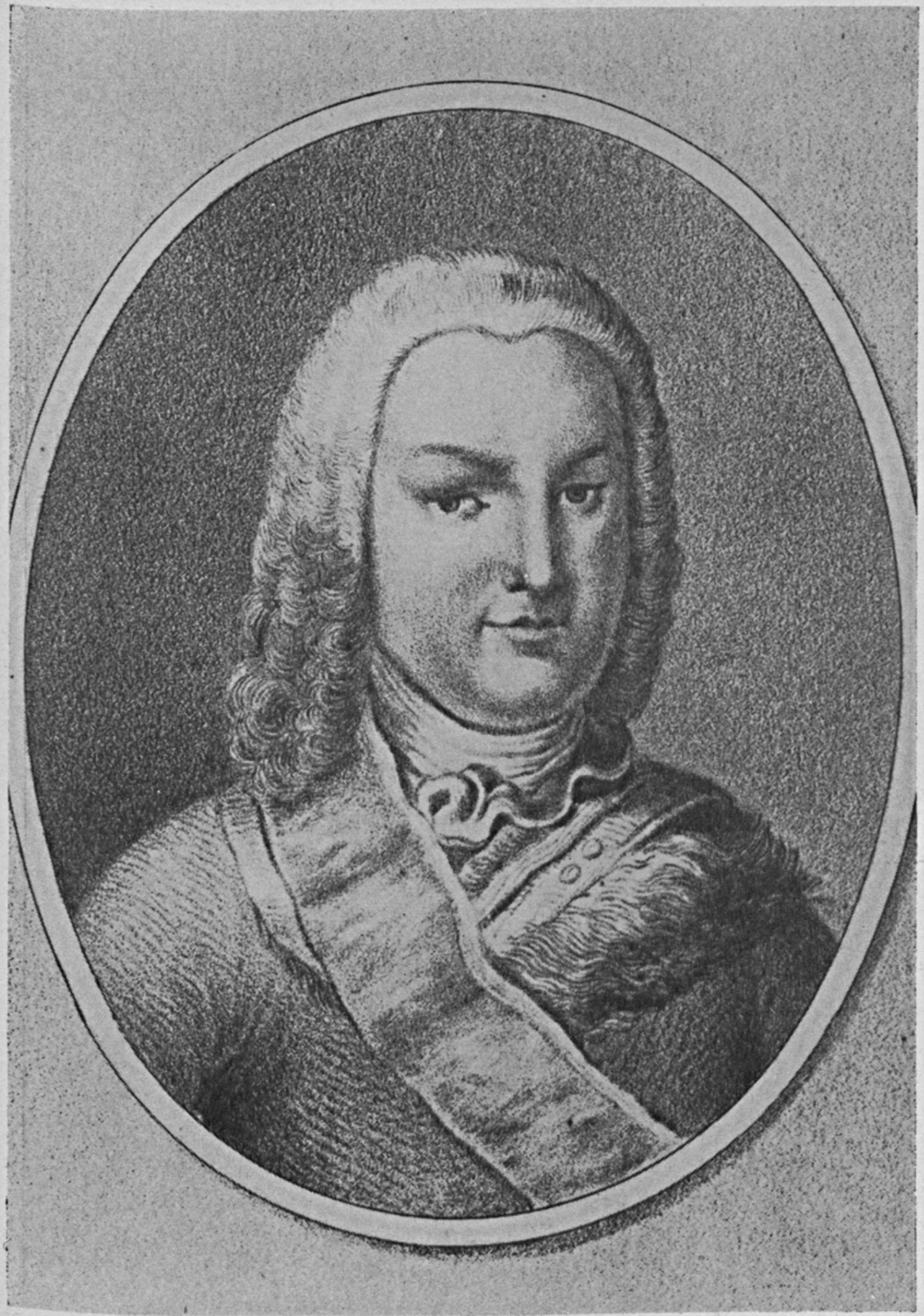

3. Fernando VI. Litografia del libro Disertaciones Históricas de Lucas Alamán. 


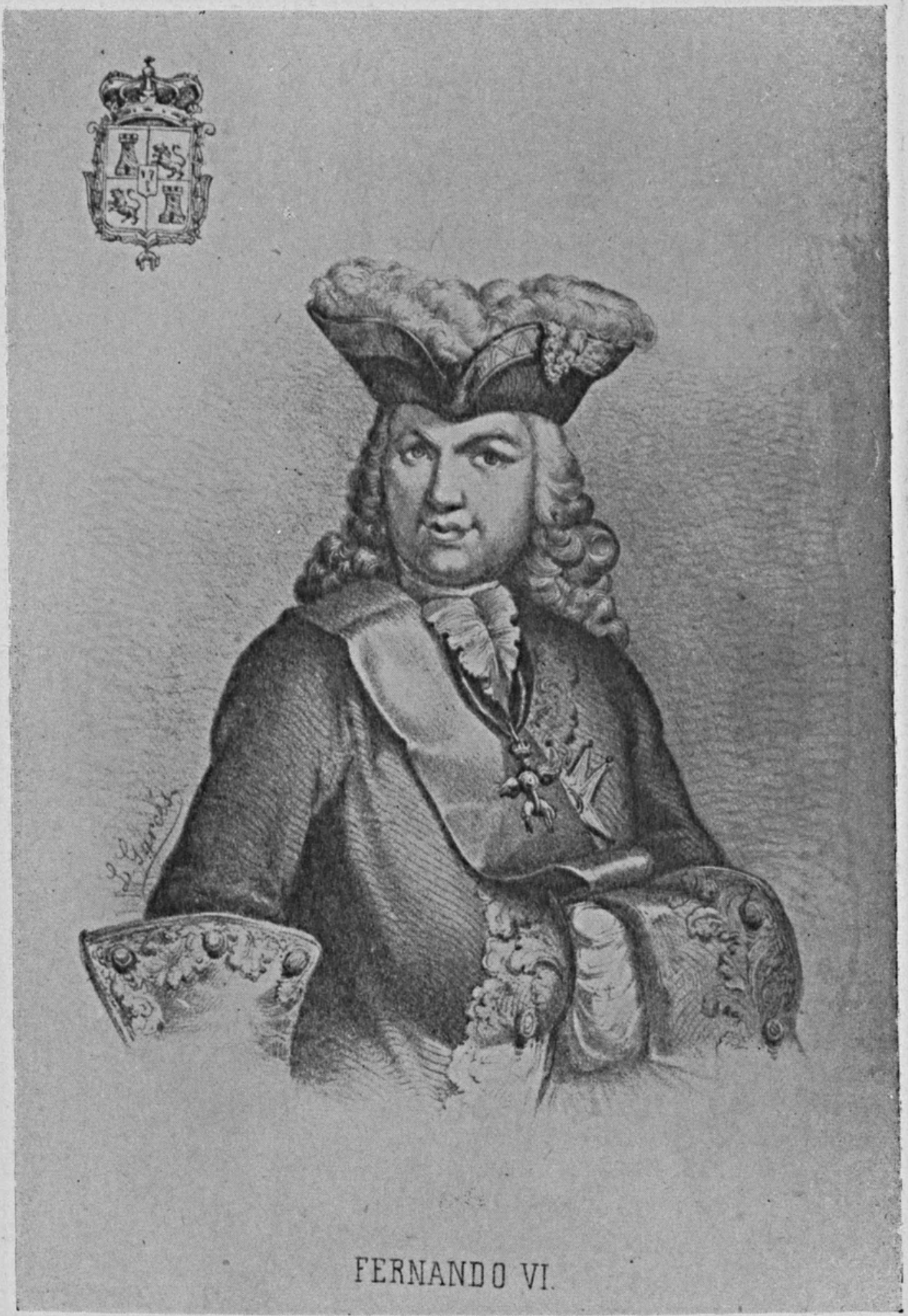

4. Fernando VI. Litografía de Luis Garcés, del libro Los Gobernantes de México. 

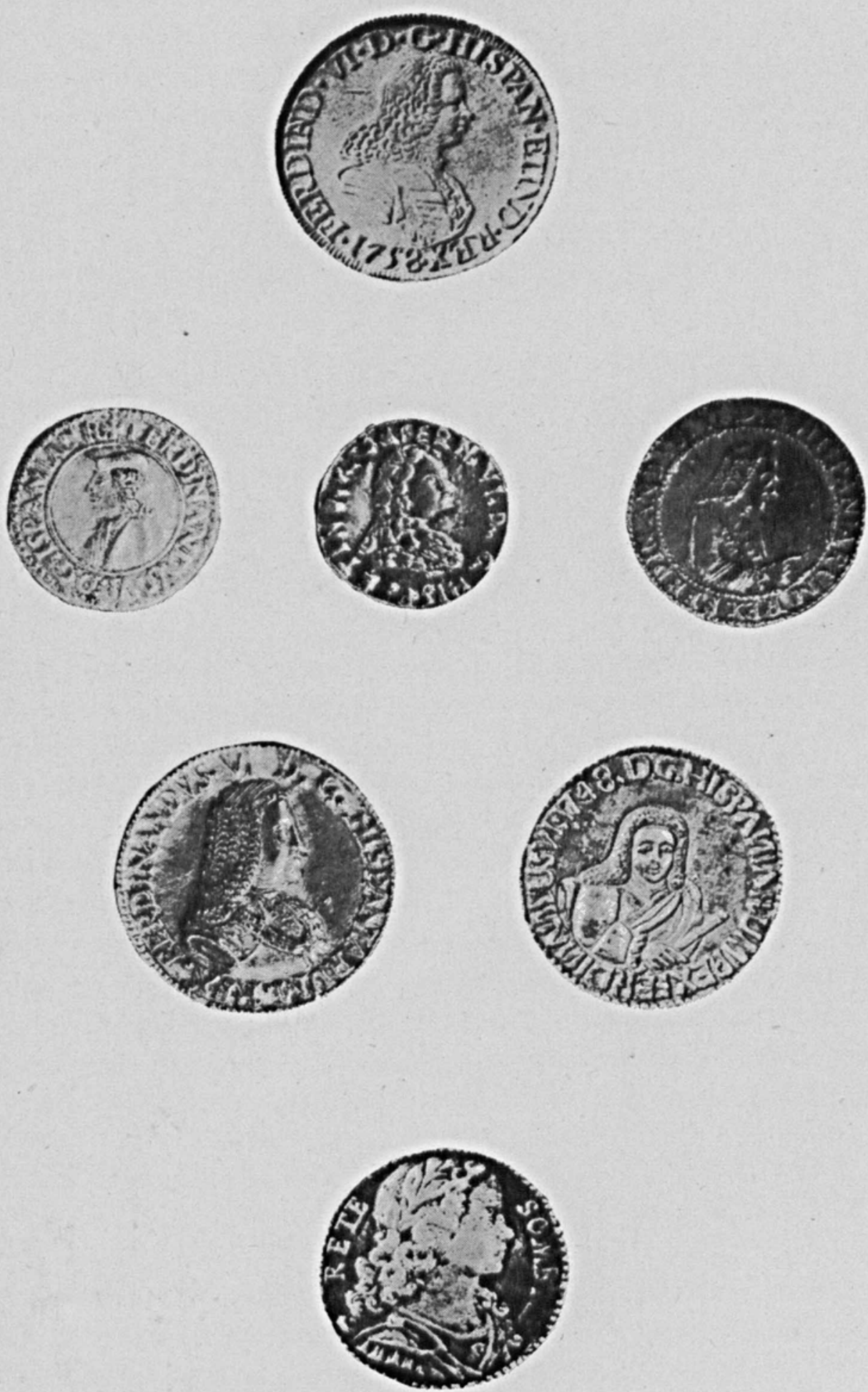

1. Moneda de oro de ocho escudos. 2. Medallas de Proclamación, de plata, de Cholula. 3. de Guanajuato. 4. de la Ciudad de México. 5. del Consulado. 6. de San Miguel el Grande. 7. de Sombrerete. 